\title{
Redescription of Cetorhinicola acanthocapax Beveridge \& Campbell, 1988 (Cestoda: Trypanorhyncha) from the basking shark Cetorhinus maximus (Gunnerus)
}

\author{
I. Beveridge $\cdot$ C. Duffy
}

Published online: 12 July 2006

(C) Springer Science+Business Media B.V. 2006

Owing to an error in the production process Figures 10-13 and 14-17 have been incorrectly reproduced:

Systematic Parasitology (2005) 62: 191-198

Redescription of Cetorhinicola acanthocapax Beveridge \& Campbell, 1988 (Cestoda: Trypanorhyn- cha) from the basking shark Cetorhinus maximus (Gunnerus)

I. Beveridge C. Duffy

The correct figures are shown on the next pages.

I. Beveridge $(\bowtie)$

Department of Veterinary Science, Veterinary Clinical

Centre, University of Melbourne, Werribee, Victoria

3030, Australia

e-mail: ibeve@unimelb.edu.au

C. Duffy

Department of Zoology, University of Canterbury,

Christchurch, New Zealand 

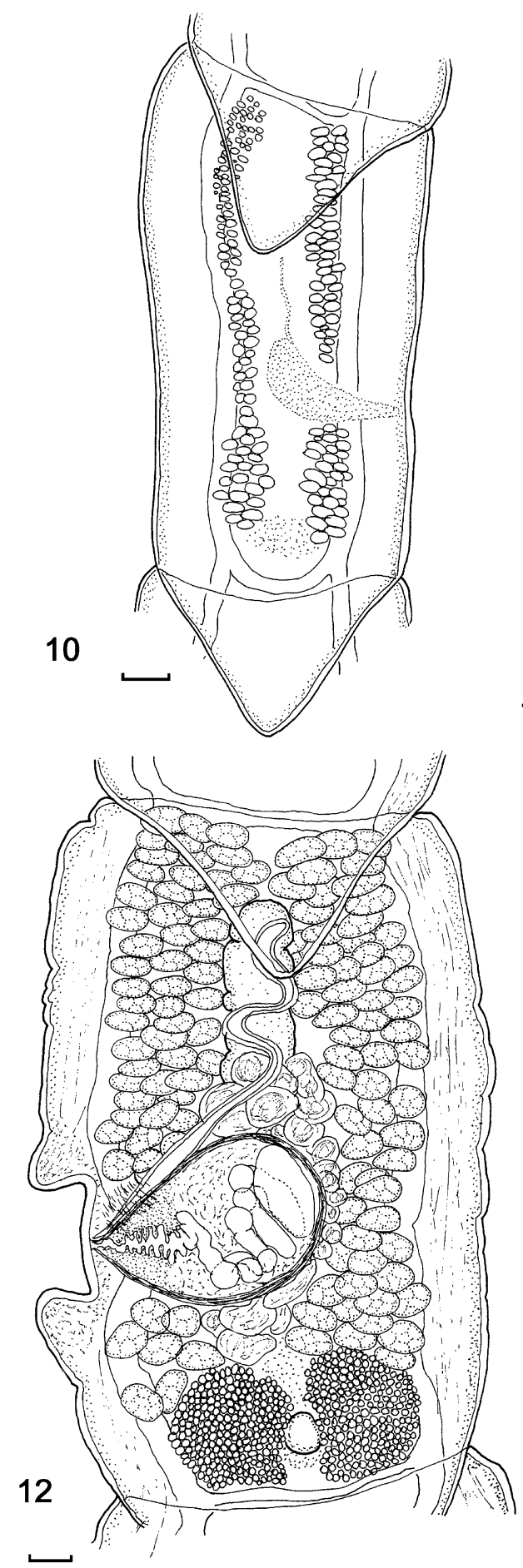

11
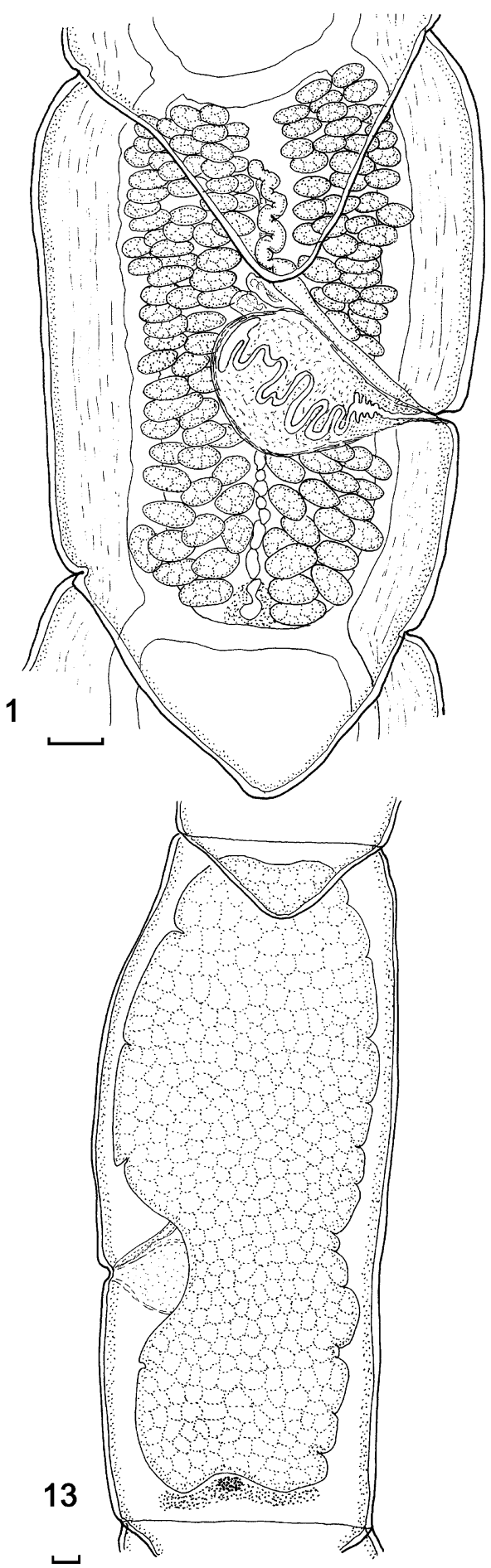

Figs. 10-13 Cetorhinicola acanthocapax Beveridge \& Campbell, 1988, pre-mature, mature and pre-gravid segments. 10. Premature segment showing the arrangement of testes in two

columns. 11. Mature segment prior to the development of the ovary. 12. Mature segment with ovary fully developed and uterus starting to enlarge. 13. Pre-gravid segment. Scale-bars: $100 \mu \mathrm{m}$ 


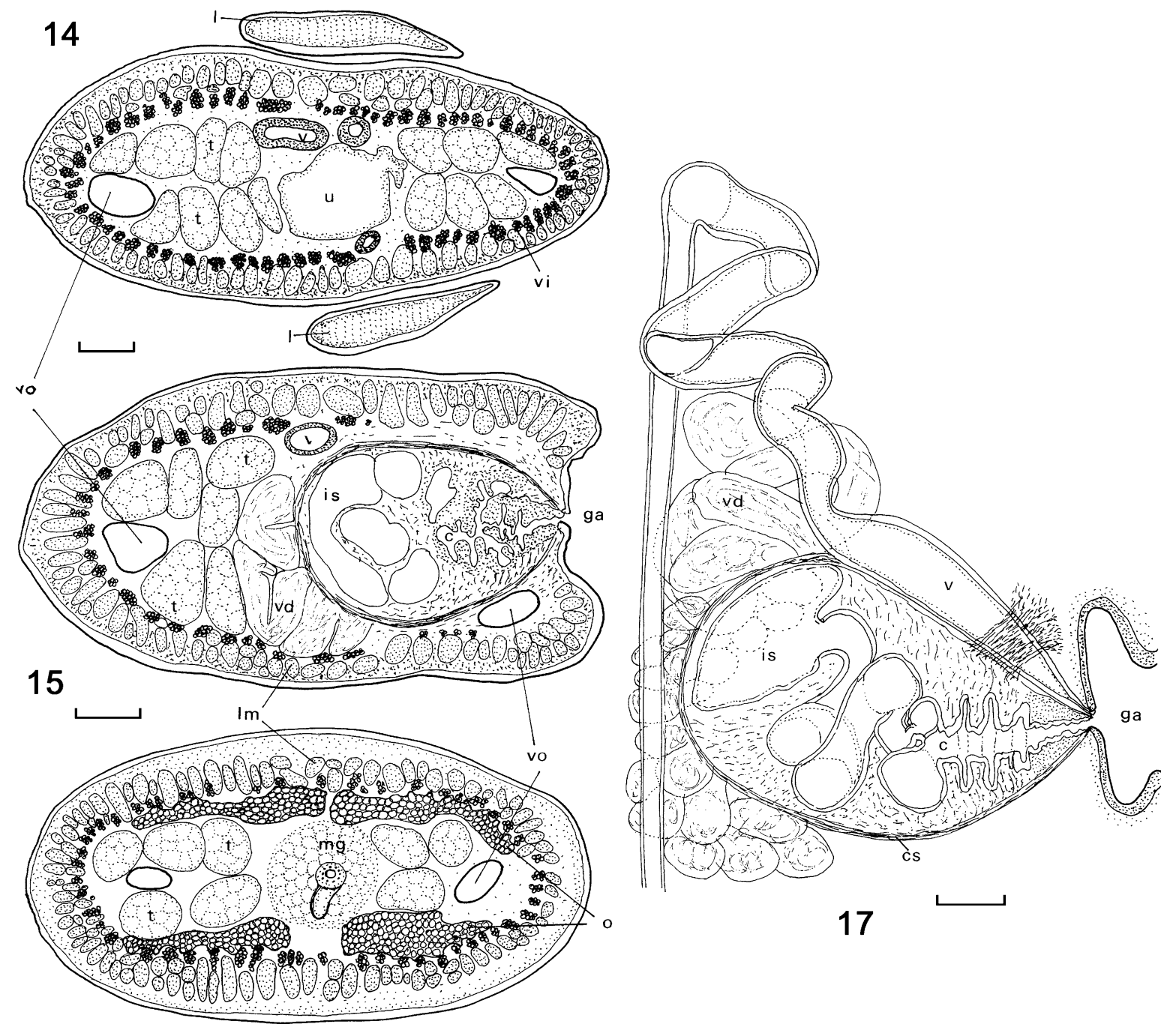

\section{6}

Figs. 14-17 Cetorhinicola acanthocapax Beveridge \& Campbell, 1988, transverse sections through mature segments and dorsoventral illustration of the terminal genital ducts. 14 . Transverse section through the anterior region of a segment, including the lappets of the preceding segment. 15. Transverse section of a mature segment through the genital atrium showing the cirrus-sac. 16. Transverse section of a mature segment at the level of the ovary and Mehlis' gland. 17. Dorsoventral view of the genital ducts. Abbreviations: c, cirrus; cs, cirrus-sac; ga, genital atrium; is, internal seminal vesicle; 1 , lappet; lm, longitudinal muscle; mg, Mehlis' gland; o, ovary; sp, sphincter; t, testis; u, uterus; v, vagina; vd, vas deferens; vi, vitelline follicle; vo, ventral osmoregulatory canal. Scale-bars: $100 \mu \mathrm{m}$ 